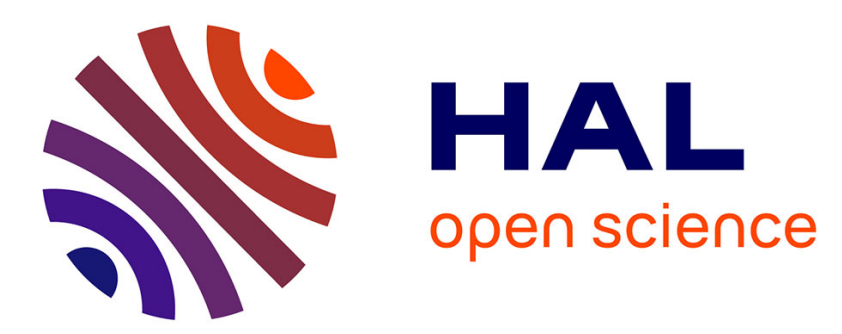

\title{
Post-translational modifications in Plasmodium: More than you think!
}

Duk-Won Doug Chung, Nadia Ponts, Serena Cervantes, Karine G Le Roch

\section{To cite this version:}

Duk-Won Doug Chung, Nadia Ponts, Serena Cervantes, Karine G Le Roch. Post-translational modifications in Plasmodium: More than you think!. Molecular and Biochemical Parasitology, 2009, 168 (2), pp.123-134. 10.1016/j.molbiopara.2009.08.001 . hal-02665112

\section{HAL Id: hal-02665112 https://hal.inrae.fr/hal-02665112}

Submitted on 31 May 2020

HAL is a multi-disciplinary open access archive for the deposit and dissemination of scientific research documents, whether they are published or not. The documents may come from teaching and research institutions in France or abroad, or from public or private research centers.
L'archive ouverte pluridisciplinaire HAL, est destinée au dépôt et à la diffusion de documents scientifiques de niveau recherche, publiés ou non, émanant des établissements d'enseignement et de recherche français ou étrangers, des laboratoires publics ou privés. 
Review

\title{
Post-translational modifications in Plasmodium: More than you think!
}

\author{
Duk-Won Doug Chung, Nadia Ponts, Serena Cervantes, Karine G. Le Roch* \\ Department of Cell Biology and Neuroscience, University of California, Riverside, 900 University Avenue, Riverside, CA 92521, USA
}

\section{A R T I C L E I N F O}

\section{Article history:}

Received 7 May 2009

Received in revised form 10 July 2009

Accepted 3 August 2009

Available online 8 August 2009

\section{Keywords:}

Plasmodium

Post-translational modification

Kinases

Proteases

Ubiquitin system

Life-cycle regulation

\begin{abstract}
A B S T R A C T
Recent evidences indicate that transcription in Plasmodium may be hard-wired and rigid, deviating from the classical model of transcriptional gene regulation. Thus, it is important that other regulatory pathways be investigated as a comprehensive effort to curb the deadly malarial parasite. Research in post-translational modifications in Plasmodium is an emerging field that may provide new venues for drug discovery and potential new insights into how parasitic protozoans regulate their life cycle. Here, we discuss the recent findings of post-translational modifications in Plasmodium.
\end{abstract}

Published by Elsevier B.V.

\section{Contents}

1. Introduction . .

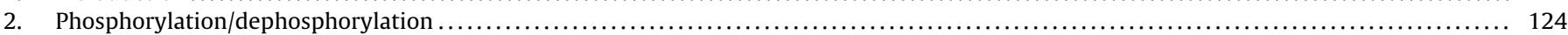

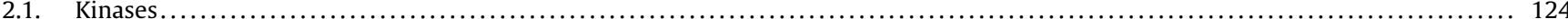

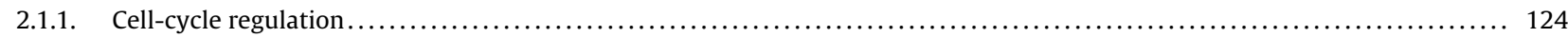

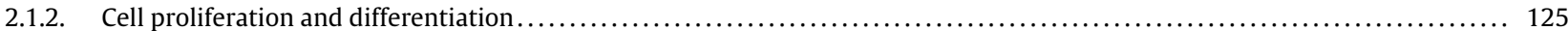

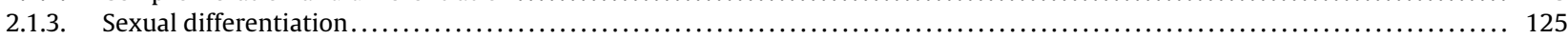

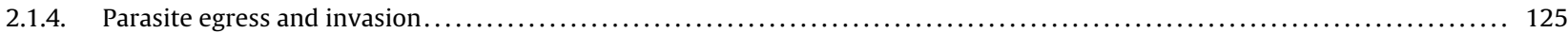

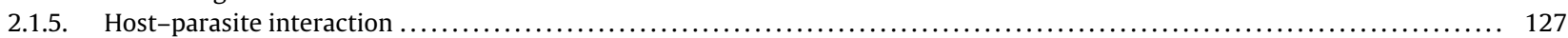

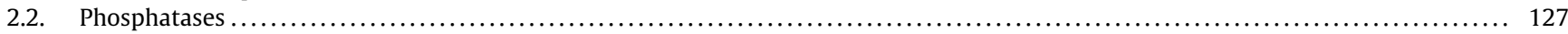

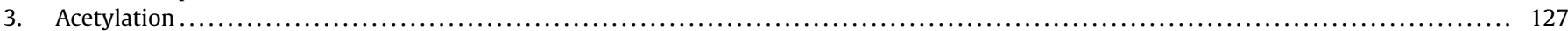

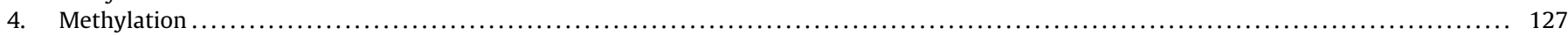

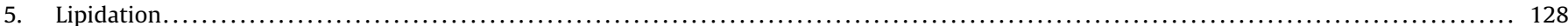

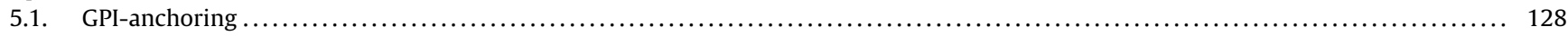

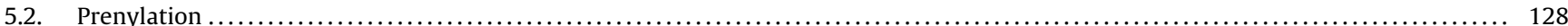

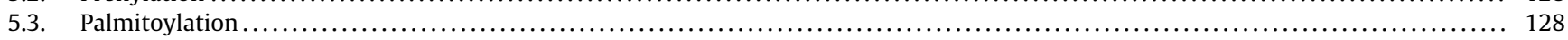

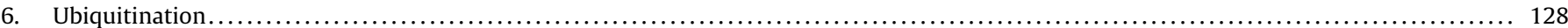

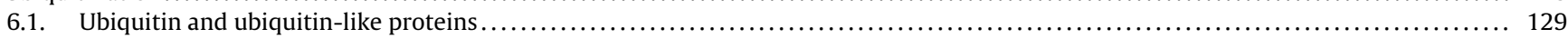

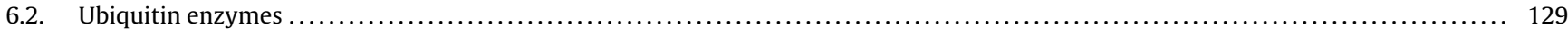

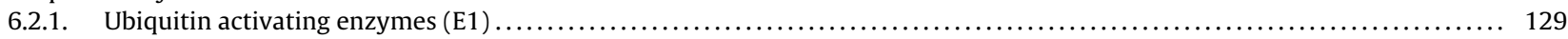

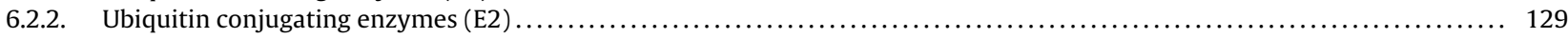

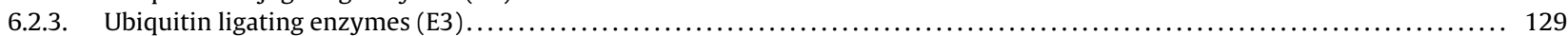

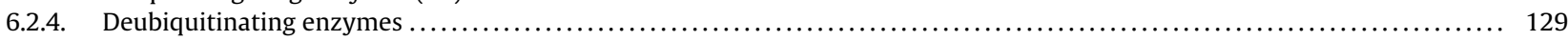

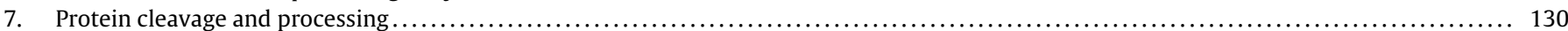

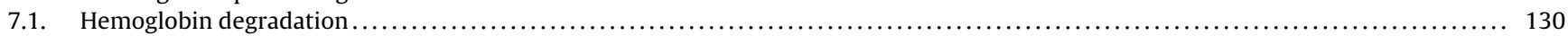

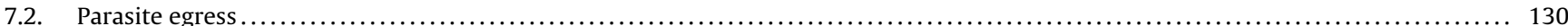

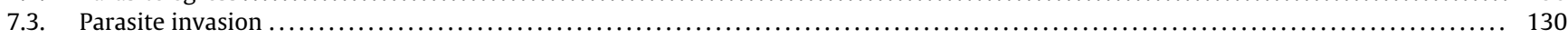

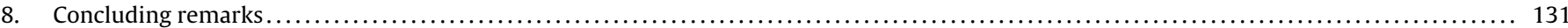

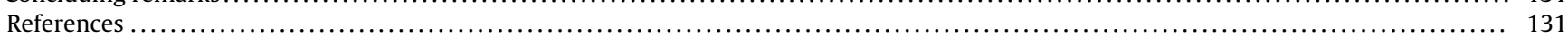

\footnotetext{
* Corresponding author. Tel.: +1 9518275422.

E-mail address: karine.leroch@ucr.edu (K.G. Le Roch).
} 


\section{Introduction}

Malaria is one of the deadliest infectious diseases of the world. Each year, malaria infects over 300 million people world-wide and causes an estimated one to two million deaths [1-3]. With the increase of drug resistance to most of the widely used anti-malarial drugs, it is imperative to better understand key regulatory elements driving the Plasmodium life cycle, eventually leading to the discovery of new drug targets.

The sequencing of the Plasmodia genomes, along with subsequent comparative bioinformatics approaches, transcriptome and proteome analyses, have created a vast amount of information regarding protein prediction and their hypothetical functions in both the human host and mosquito vector [4-7]. While microarray analyses have demonstrated a remarkable change in steady-state mRNA levels during parasite development, only relatively few regulatory motifs and transcription regulators have been uncovered so far [8]. In addition, unlike other organisms, there seems to be few transcriptional changes in Plasmodium following exposure to external stimuli $[3,9,10]$. These findings imply that parasite transcription could be hard-wired [10]. This rigidity in transcription suggests that post-transcriptional and post-translational mechanisms are likely to play major roles in regulating the parasite life cycle.

By definition, post-translational modifications (PTMs) must add or subtract a specific mass difference and not be particular to any one protein [11]. In addition to changing protein mass, PTMs can also alter the protein charge and conformation. Such changes modify the protein's enzyme activity, binding affinity and hydrophobicity [12]. The spectrum of the PTMs within a cell is immense and varies with respect to specificity and abundance. For example, some types of PTMs such as phosphorylation and ubiquitination are universally employed to regulate a broad host of functions, have relatively high abundance, and have a wide range of target substrates. On the other hand, some PTMs such as acetylation are highly specific in their roles, have a relatively low abundance, and may target only a few proteins or even one target substrate at a time. Furthermore, PTMs can either modify a protein at one specific amino acid residue or be associated with numerous different residues. The potential diversity of protein modifications seem limitless due to the fact that an individual protein can undergo a single modification or multiple types of modifications at several sites, possibly producing multiple protein isoforms, each with a unique biological activity. One can easily see why PTMs are responsible for a major increase in complexity from genome to proteome. For example, the human genome contains approximately 30,000 open reading frames but is predicted to give rise to roughly 1.8 million different protein variants [13].

Furthermore PTMs are reversible and thus provide the flexibility and adaptability that are essential for mediating rapid cellular responses to the cell's constantly changing conditions. Thus, posttranslational modifications are vital for the survival of all kinds of cells, with Plasmodium not being an exception. Due to their diversity, essentiality, and wide-spread roles, post-translational modifications could present new major targets for effective and specific therapeutic intervention against the malarial parasite. Here we present an overview of the major post-translational modifications found so far in Plasmodium and discuss the recent developments of this rapidly expanding field. A summary of the major proteins involved in regulating PTMs in Plasmodium is also presented in Fig. 1 and Table 1.

\section{Phosphorylation/dephosphorylation}

Phosphorylation involves the reversible esterification of a phosphate group to an amino acid residue by protein kinases (PKs) that transfer a phosphoryl group from an ATP to hydroxyamino acid residues, mostly serine, threonine and tyrosine [14]. As the most highly studied covalent modification of proteins in eukaryotic cells, phosphorylation events can be linked to practically most functions within a cell: cell growth, cell differentiation, receptor activations, metabolic pathways, enzyme activities, cytoskeletal organization, chromatin remodeling, protein activations/inhibitions and protein-protein interactions. Approximately $1.5-2 \%$ of genes in an eukaryotic genome are PK family genes, which reflects the importance of phosphorylation events. While protein kinases catalyze the phosphorylation of protein residues, phosphatases hydrolyze the phosphoester bond of the modified amino acid, restoring the hydroxyamino acid to its unphosphorylated state [15]. In eukaryotes, the number of protein phosphatases is relatively small when compared to that of protein kinases. However, additional phosphatase regulatory proteins mediate specific regulation of these enzymes and it is speculated that the number of phosphatase complexes involved in regulatory pathways may exceed the protein kinases repertoires [16].

\subsection{Kinases}

Several kinase inhibitors have been shown to inhibit Plasmodium development at different stages of the life cycle [9,17-20] validating the importance of phosphorylation in maintaining the parasite. Depending on the stringency applied, computational analyses retrieved 86-99 PK-related enzymes from the Plasmodium falciparum (Pf) genome [21,22]. Phylogenetic studies have demonstrated that most of the eukaryotic families of PKs are present in the Plasmodium genome with the exception of two groups, ste20 (STE) and the tyrosine protein kinases (TyrK) families. The STE family includes PKs involved in Mitogen-activated protein kinase (MAPK) cascades and plays a central role in transduction signals (see reference Ward et al., 2004 for further details). This group is evolutionarily conserved and their absence in the parasite genome may indicate that the mode of activation of the MAPK pathway in the parasite differs from other eukaryotes. The TyrKs are known to function in hormone-response receptor-linked pathways essential for intercellular communication in multicellular organisms and are therefore not expected in the malaria parasite.

Several "orphan" PKs have also been identified in the Plasmodium kinome. They display only limited similarities with yeast or mammalian kinases. Examples of these atypical kinases include the NIMA-related kinase Nek1 (PFL1370W) [17], twenty FIKK PKrelated proteins, found only in apicomplexan parasites [22,23], and a family of calcium-dependant kinases (CDPKs) that are usually found in plants and alveolate but not in metazoans [24]. In the following section we briefly describe the key biological functions identified so far for a few selected Plasmodium kinases.

\subsubsection{Cell-cycle regulation}

In eukaryotes, kinases are known to play a major role in cellcycle progression. This is particularly the case for cyclin-dependent kinases (CDKs), several of which have been identified in the Pf genome [22]. Two Pf CDKs, PfPK5 (MAL13P1.279) and Pfmrk (PF10_0141), have been shown to be positively regulated by the binding of Plasmodium and mammalian cyclins as well as negatively regulated by $C D K$ inhibitors [25-27]. These results demonstrate that regulatory activities of CDKs are well-conserved across species. While the targets of these Plasmodium kinases have not yet been identified, it is speculated that such proteins might play a major role in the regulation of the parasite schizogony and its nuclear division cycles [28]. In vitro biochemical characterizations and crystal structure analyses have uncovered possible unique regulatory mechanisms of Plasmodium CDKs [27,29]. Such particularities indicate an atypical mode of DNA replication/mitosis in the parasite [30]. Furthermore, an atypical Pf orphan protein kinase, PfPK7 


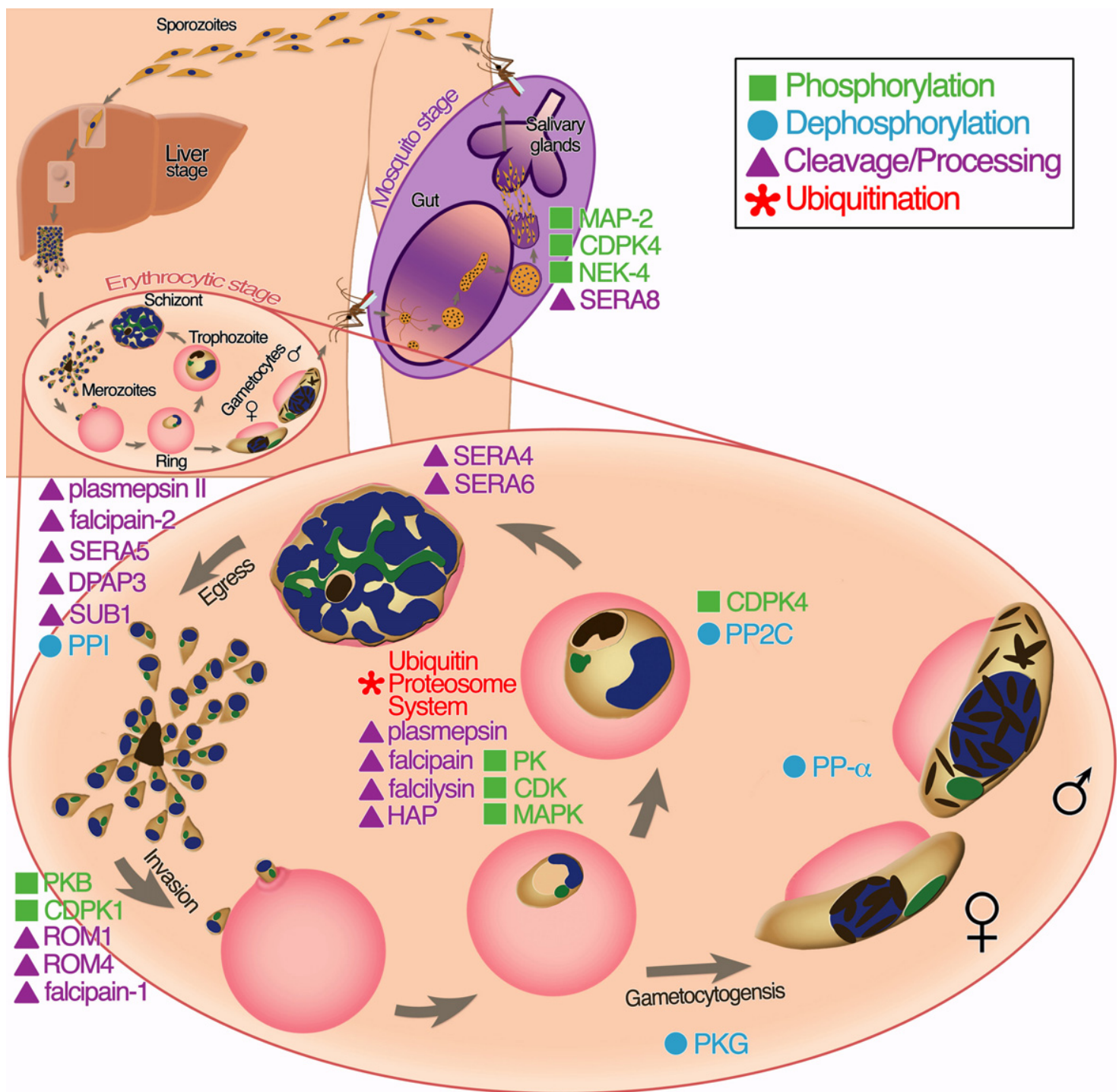

Fig. 1. General depiction of the roles of a few selected proteins involved in post-translational modifications during the life cycle of the malaria parasite.

(PFB0605w), that exhibits maximal homology to a MEKKK and a fungal PKA has been shown to regulate parasite proliferation and development [31]. Discrepancies observed between parasite and host kinases may be exploited in the search of parasite-specific kinase inhibitors as potential anti-malarial drugs but would need to be further validated in vivo.

\subsubsection{Cell proliferation and differentiation}

MAPKs are known to be key players in signal transductions, cell development and differentiation in response to a variety of stimuli [32]. Though no classical MAPK kinase has been identified in the Plasmodium genome, two atypical MAPK homologs have been characterized, Pfmap-1 (PF14_0294) and Pfmap-2 (PF11_0147). While the exact role of Pfmap-1 is still speculated, Pfmap-2 appears to be essential for the completion of the parasite asexual erythrocytic cycle [33]. However in Plasmodium berghei ( $P b)$, the Pfmap-2 orthologue seems to be essential to parasite exflagellation in the mosquitos midgut [34]. Discrepancies observed between these two Plasmodium species will need to be further clarified. Nonetheless, it is possible to envision a complementation effect induced by species-specific Plasmodium kinases.

\subsubsection{Sexual differentiation}

Several identified Plasmodium kinases have been implicated in sexual differentiation. In $\mathrm{Pb}$, a calcium-dependant kinase (CDPK4, PF07_0072 in $P f$ ) has been shown to regulate gamete formation with the initiation of DNA replication, ookinate gliding mobilities, and mosquitos midgut invasion [35-37]. cGMP-dependant protein kinase (PFPKG, PF14_0346 in Pf) seems to be essential for mediating initiation of gametocytogenesis [18]. Finally, the $P b$ Pbnek-4 (MAL7P1.100 in Pf) has been shown to be critical for ookinate maturation [38]. The detection of an increased number of protein kinases involved in sexual differentiation demonstrates that PKs have a crucial role in regulating gametocytogenesis. These preliminary results provide a framework for identifying substrates of these Plasmodium enzymes to further comprehend the signalling cascade involved in sexual differentiation.

\subsubsection{Parasite egress and invasion}

In contrast to other pathogens, apicomplexans such as Plasmodium can quickly exit and enter the cell using their own machinery. Several steps involving a large collection of proteins are required in erythrocytic egress and invasion [39]. From this collection, a few protein kinases have been shown to have a role in controlling these 
Table 1

Genes that are putatively involved in post-translational modifications in Plasmodium.

\begin{tabular}{|c|c|c|c|c|}
\hline Modification & Type of protein & Protein name & Gene ID & Putative role \\
\hline \multirow[t]{14}{*}{ Phosphorylation } & Casein kinase & CK1 & PF11_0377 & Unknown [20] \\
\hline & Cyclin-dependent kinase & PK5 & MAL13P1.279 & Cell-cycle regulation [25-27] \\
\hline & Cyclin-dependent kinase & mrk & PF10_0141 & Cell-cycle regulation [25-27] \\
\hline & $\begin{array}{l}\text { Serine/threonine protein } \\
\text { kinase }\end{array}$ & PK7 & PFB0605w & Proliferation and development [31] \\
\hline & $\begin{array}{l}\text { Mitogen-activated protein } \\
\text { kinase }\end{array}$ & map-1 & PF14_0294 & Unknown [33] \\
\hline & $\begin{array}{l}\text { Mitogen-activated protein } \\
\text { kinase }\end{array}$ & map-2 & PF11_0147 & Asexual cycle regulation [33] \\
\hline & $\begin{array}{l}\text { Mitogen-activated protein } \\
\text { kinase }\end{array}$ & map-2 & PB000659.00.0 & Exflagellation in mosquito midgut [34] \\
\hline & Calcium-dependent kinase & CDPK4 & PF07_0072 & $\begin{array}{l}\text { DNA replication, ookinete gliding mobility, mosquito midgut } \\
\text { invasion [35-37] }\end{array}$ \\
\hline & $\begin{array}{l}\text { cGMP-dependant protein } \\
\text { kinase }\end{array}$ & PKG & PF14_0346 & Gametocytogenesis initiation [18] \\
\hline & NIMA-related kinase & nek-4 & MAL7P1.100 & Ookinete maturation [38] \\
\hline & Calmodulin-like protein kinase & CDPK1 & PFB0815w & $\begin{array}{l}\text { Secretion of microneme contents, formation of tight moving } \\
\text { junctions [40] }\end{array}$ \\
\hline & Protein kinase B & PKB & PFL2250c & Parasite gliding [41] \\
\hline & Protein kinase A & PKA & PFI1685w & $\begin{array}{l}\text { Mediates erythrocyte anion channels and permeability of host } \\
\text { plasma membrane [44-45] }\end{array}$ \\
\hline & FIKK orphan kinases & Multiple proteins & Multiple genes & Targets parasite proteins to host membranes [46] \\
\hline \multirow[t]{4}{*}{ Dephosphorylation } & $\begin{array}{l}\mathrm{Mg}^{2+} \text {-dependent } \\
\text { serine/threonine protein } \\
\text { phosphatase } 2 \mathrm{C}\end{array}$ & PP2C & Multiple genes & Transcription elongation [55] \\
\hline & VH1 family phosphatases & YVH1 & Multiple genes & Nuclear protein activity [56] \\
\hline & Protein phosphatase 1 & PP1 & Multiple genes & Release of infection merozoites [57] \\
\hline & $\begin{array}{l}\text { PPP-related protein } \\
\text { serine/threonine phosphatase }\end{array}$ & PP- $\alpha$ & Multiple genes & Cell-cycle control and signal transduction in sexual stages [50] \\
\hline \multirow[t]{2}{*}{ Lipidation } & Prenyl modifier & PFT $\alpha$-subunit & PFL2050w & Unknown [88] \\
\hline & Prenyl modifier & PFT $\beta$-subunit & PF11_0483 & Unknown [88] \\
\hline \multirow[t]{6}{*}{ Ubiquitination } & Ubiquitin & pUB & PFL0585w & $\begin{array}{l}\text { Polyubiquitin gene that provides the ubiquitin monomers that } \\
\text { are covalently attached to proteins. Cell-cycle regulation [106] }\end{array}$ \\
\hline & Ubiquitin & UbS27a & PF13_0346 & $\begin{array}{l}\text { Ubiquitin moiety that provide the ubiquitin monomers for } \\
\text { attachment to proteins. Cell-cycle regulation [108] }\end{array}$ \\
\hline & Ubiquitin & UbL40 & PF14_0027 & $\begin{array}{l}\text { Ubiquitin moiety that provide the ubiquitin monomers for } \\
\text { attachment to proteins. Cell-cycle regulation [108] }\end{array}$ \\
\hline & SUMO & PfSUMO & PFE0285c & $\begin{array}{l}\text { Ubiquitin-like peptide that is covalently attached to proteins } \\
\text { for DNA repair, cell-cycle regulation, nuclear localization and } \\
\text { protein stability [110] }\end{array}$ \\
\hline & E2 conjugating enzyme & UBC13 & PFE1350c & $\begin{array}{l}\text { Was found to be phosphorylated by PfPK9. Role in cell-cycle } \\
\text { has to be validated in Plasmodium [111] }\end{array}$ \\
\hline & $\begin{array}{l}\text { Deubiquitylating/DeNeddylating } \\
\text { enzyme }\end{array}$ & UCH54 & PF14_0576 & $\begin{array}{l}\text { Has dual deubiquitylating and deNeddylating activity. May } \\
\text { have roles in maintaining stable apical membrane epithelial } \\
\mathrm{Na}+\text { channels [118] }\end{array}$ \\
\hline \multirow[t]{21}{*}{ Cleavage/Processing } & Serine protease & Subtilisin-1 (SUB1) & PFE0370c & Activates SERA proteins. Primary regulator of egress [143] \\
\hline & & Subtilisin-2 (SUB2) & PF11_0381 & Shedding of MSP-1 and PfAMA-1 after invasion [151] \\
\hline & & Subtilisin-3 (SUB3) & PFE0355c & Ubiquitous role [144] \\
\hline & & ROM-1 & PF11_0150 & Shedding of adhesins [147] \\
\hline & & ROM-1 & PB000352.00.0 & May have roles in invasion [149] \\
\hline & & ROM-4 & PFE0340c & Shedding of adhesins [146] \\
\hline & & SP1 & PF13_0118 & Cleavage of transit peptide [123] \\
\hline & Cysteine protease & Falcipain-1 & PF14_0553 & Putative role in invasion [153] \\
\hline & & Falcipain-2 & PF11_0165 & Hemoglobinase \& role in egress [132] \\
\hline & & Falcipain-3 & PF11_0162 & Hemoglobinase [132] \\
\hline & & SERA-4 & PFB0345c & Expressed in the PV at the late schizont stage [140] \\
\hline & & SERA-5 & PFB0340c & Role in merozoite egress [139] \\
\hline & & SERA-6 & PFB0335c & Expressed in the PV at the late schizont stage [140] \\
\hline & & SERA-8 & PFB0325c & Sporozoite release from oocystes [141] \\
\hline & & DPAP3 & PFD0230c & Primary regulator of egress [142] \\
\hline & & Calpain & MAL13P1.310 & Unknown [132] \\
\hline & Metallo protease & Falcilysin & PF13_0322 & Hemoglobinase [125] \\
\hline & Aspartic protease & Plasmepsin I & PF14_0076 & Initiate degradation of hemoglobin [133] \\
\hline & & Plasmepsin II & PF14_0077 & Initiate degradation of hemoglobin \& role in egress [133] \\
\hline & & Plasmepsin IV & PF14_0075 & Cleavage of denatured globin [133] \\
\hline & & $\begin{array}{l}\text { Histo-aspartic } \\
\text { protease (HAP) }\end{array}$ & PF14_0078 & Cleavage of denatured globin [133] \\
\hline
\end{tabular}


parasitic processes. The calmodulin-like PK (CDPK1, PFB0815w in $P f)$ is required for the secretion of the parasite microneme contents and the formation of tight moving junctions [40]. Two components of the acto-myosin motor complex, the myosin A tail domain interacting protein (MTIP) and the glideosome-associated protein 45 (GAP45) have been identified to be CDPK1 substrates. In addition, PfPKB (PFL2250c) [41], an important member of the phosphatidylinositol 3-kinase-dependent signaling pathway, has been implicated to regulate parasite gliding mechanisms $[42,43]$. However, validating the role of PfCDPK1 and PfPKB in vivo remains to be established.

\subsubsection{Host-parasite interaction}

Recent works have begun to reveal the importance of Plasmodium PKs in modulating the erythrocyte membranes of infected hosts. PfPKA (PFI1685w) has been shown to alter both the activity of an erythrocyte anion channel and the permeability of the host plasma membrane [44,45]. Interestingly, the members of the Plasmodium FIKKs orphan kinases possess a Plasmodium export element (PEXEL) motif [46] that target parasite proteins to the host membrane $[47,48]$. Immuno-microscopy reveals that many FIKK proteins can be found in the erythrocyte cytoplasm and colocalized with Maurer's clefts protein. This finding suggests the importance of these FIKKs in the remodeling of the infected erythrocyte membrane [46].

While it is increasingly apparent that a significant number of protein kinases regulate major parasite cell cycle and differentiation events, our understanding of their targeted substrates is extremely limited. In order to comprehend the function and essentiality of each kinase, a systematic biological approach involving reverse genetics, chemical genetics and phosphoproteome studies will need to be developed.

\subsection{Phosphatases}

A total of twenty-seven malaria protein phosphatases (PP) have been identified in the Pf genome (reviewed by [49]). The identified Plasmodium PP clustered with the four major established eukaryotic PP families: the Metallophosphatases (PPP), the Serine/Threonine Phosphatases (PPM), the Protein Tyrosine Phosphatases (PTP) and the NLI Interacting Factor-like phosphatases (NIF). Protein sequence information as well as biochemical characterizations studies of several of these PPs in Plasmodium have validated their phosphatase activities and revealed significant differences with other eukaryotic organisms [49-52].

The use of phosphatase inhibitors have shown that Plasmodium PPs are essential and may be involved in invasion [53] and cell growth [54]. Protein-protein interaction and localization studies have highlighted a role of Plasmodium PPs in transcriptional elongation [55], nuclear protein activity [56] and the release of infectious merozoites [57]. Interestingly, highly conserved eukaryotic phosphatases seem to be either missing or too divergent to be detected in the Plasmodium genome. Among the missing phosphatases are the CDC25 homologue (known to play a major role in cell cycle control) [58], the cdc14 phosphatase (regulates mitotic events) [59] and tyrosine phosphatases [60] (though there is a report of a possible PRL tyrosine phosphatase) [61]. These findings further validate the phylogenetic distance observed between Plasmodium spp. and its vertebrate host. The identification of PP regulatory subunits, as well as their specific substrates, will need to be further investigated. However, it has become evident that these PPs are essential to the parasite and should be considered as potential targets for new anti-malarial strategies.

\section{Acetylation}

Acetylation is the addition of an acetyl functional group onto a protein substrate. Acetyltransferases transfer an acetyl group from acetyl coenzyme A onto conserved $\mathrm{N}$-terminal lysine residues. The result of acetylation usually modifies DNA binding properties, protein stability, and protein-protein interactions.

Acetylation of actin at the N-terminus is a highly conserved PTM that has also been reported in Pf [62]. In addition to actin, Plasmodium histones are found to be acetylated at their N-terminal lysine residues [63]. Histone PTMs are a vital part of the "histone code' hypothesis that proposes specific combinations of PTMs that modify chromatin structure and act as platforms for the binding of transcriptional regulators of gene expression. Consistent with other eukaryotes, Plasmodium histone acetylation is believed to play a major role in transcriptional regulation. In a genome-wide investigation of histone modifications and their relationship with transcriptional activation/silencing, Cui et al. (2007) [64] employed a combination of immunoprecipitation and DNA microarray detection (ChIP-chip) to show that acetylation of histone H3 (H3K9ac) was associated with active genes across the Pf genome. PfGCN5 was the first characterized histone acetyltransferase (HAT) subunit identified in Plasmodium. Recombinant PfGCN5 displayed histone $\mathrm{H} 3$ acetylase activity in vitro and exists as a catalytic subunit of $P$. falciparum HAT complex. PfADA2, the yeast transcriptional coactivator homolog, has been characterized as another component of the trimeric catalytic core [65]. In vitro pull-down and yeast twohybrid experiments suggest that PfADA2 and PfGCN5 are present in complex(es) and may have conserved chromatin remodeling functions. Natural compounds that inhibit HAT activity are being explored as potential antimalarials [66]. However, because HATs are conserved across species, toxicity studies will have to be further investigated.

Pf HDAC1 and PfSir2, two of the five putative Plasmodium Histone Deacetylases (HDACs), have been partially characterized in Plasmodium [67]. PfSir2, a yeast homolog of the silent information regulator 2 (SIR2) was found to bind to parasite telomeres and cause histone de-acetylation and silencing of the var multi-gene family [68]. Inhibitors of HDAC activity have also been investigated for potential antimalarial drugs [69,70].

\section{Methylation}

Methylation is catalyzed by methyltransferases that attach a methyl group onto its substrate. Such modification increases lipophilicity and reduces the substrate solubility in water. Methylation is associated with the regulation of gene expression and protein activity. In Plasmodium, the most commonly methylated subtrates are the parasite histones. Genomewide analysis of histone modification showed that H3K9me3 is associated with gene silencing [64]. Recently, chromatin immunoprecipitation of transcriptionally active var gene loci assessed the enrichment of histone $\mathrm{H} 3 \mathrm{di}$ - and trimethylation marks (H3K4me2 and H3K4me3) in the $5^{\prime}$ flanking region [71].

At least nine Plasmodium histone methyltransferases (HMT) (containing a SET-domain, characteristic of histone lysine methyltransferase), and two Plasmodium demethylases (containing a JumonjiC-domain, characteristic of Histone Lysine Demethylases (HDMs)) have been identified in silico. Phylogenetic analysis divided putative histone lysine methyltransferases (HKMTs) into five subfamilies with different putative substrate specificities. HKMTs and HDMs not only have substrate specificity but also specificity for different methyl states (mono-, di-, tri-) [72]. 


\section{Lipidation}

Lipidation is the covalent binding of a lipid group to a peptide chain and can change the activity and/or cellular localization of the modified protein. Often times, the attachment of a hydrophobic chain can help to anchor soluble proteins, or proteins with weak membrane-affinity, to the inner face of a membrane. Some examples of lipidation include N-myristoylation, prenylation, GPIanchor addition, and palmitoylation. Discussed below are a couple of post-translational modifications via lipidation that have been studied so far in Plasmodium.

\subsection{GPI-anchoring}

The glycosylphosphatidylinositol (GPI) anchor is a glycolipid moiety that is added to the C-terminal of proteins after translation. Such modified proteins are attached to the outer leaflet of the cell membrane. GPI-anchored proteins are ubiquitous among eukaryotic organisms and represent a very functionally diverse group that is being extensively studied in a wide-array of organisms.

Anchoring with GPI is the major type of glycosylation that are found in Plasmodium [73]. It is commonly postulated that Plasmodium proteins are glycosylated by the erythrocytic machinery (combinatorial metabolism) during the exchanges that occur between the parasitophorous vacuole and the erythrocyte cytoplasm [74]. In the human host, the parasite's GPI anchors have been linked to the pathobiology of the disease [75] and are associated with increased levels of TNF- $\alpha$ leading to a systemic inflammation reaction [76,77]. It has been found that resistance to malaria in endemic areas is associated with the production of circulant antibodies directed against the parasite's GPI anchors [75] and are common targets for vaccine research. Also, most $P$. falciparum merozoite surface proteins are GPI-anchored and are involved in erythrocyte recognition and attachment to erythrocytes before invasion (reviewed by [78]). GPIs may also be involved in postinvasion processes. The $P$. falciparum GPI-anchored rhoptry protein Pf34 (PFD0955w) is suspected to play a role in the formation of the parasitophorous vacuole $[79,80]$.

In the mosquito host (Anopheles spp.), P. falciparum GPIs may play a direct role in immune response [81,82]. The immune response in Anopheles gambiae is elicited by the parasite GPIs resulting in a significant reduction in fecundity (diminished egg production) [83]. The role of such effect on the host-parasite interactions remains open to discussion. The authors propose that the parasite may use its GPIs to trigger the mosquito immune response and "mis-direct" the specificity of the response against other pathogen-associated molecular patterns rather than ookinetes or microneme proteins essential for parasitic processes. Furthermore, the mosquito stage GPI anchored surface proteins P25 (PF10_0303) and P28 (PF10_0302) are shed during ookinete maturation and play an important role in midgut invasion [84-86]. Finally, the GPI anchor of the circumsporozoite protein (PFC0210c) plays a crucial role in sporogenesis [87]. Due to their general importance, GPIs and their biosynthesis pathway are being investigated as potential targets to antimalarial strategies.

\subsection{Prenylation}

Prenylation, also known as isoprenylation, is the posttranslational modification of proteins by covalent attachment near the carboxyl terminal of isoprenyl lipids, a 15 carbon farnesyl or a 20 carbon geranylgeranyl group [88]. The attachment of isoprenyl lipids creates a hydrophobic tail that promotes membrane association and plays an important role in cell signal transduction, vesicle trafficking, and cell-cycle progression [89]. Unlike animals, fungi and archeabacteria, which use the classical mevalonate pathway for isoprenoid synthesis, the Plasmodium synthesizes its isoprenoid precursors via the 1-deoxy-D-xylulose 5-phosphate (DOXP) pathway within its apicoplast, a plastid-like organelle [90].

Prenylation is mediated by three enzymes: protein farnesyltransferase (PFT), protein geranylgeranyltransferase type I and type II. PFT in Plasmodium has been characterized by partial purification of protein farnesyltransferase, PfPFT, and radiolabeling of prenylated proteins [88]. Prenylation precursors are incorporated into asexual synchronized parasites in a stage-specific manner with the highest amount occurring from trophozoite to schizont, and schizont to ring transitions. Dolichylation, the addition of 11 isoprene units, has also been reported in $P$. falciparum during trophozoite and schizont stages [91].

Pharmaceutical companies have invested into the development of PFT inhibitors for the treatment of cancer with a few drugs in clinical trials. Interestingly, PFT inhibitors have been found to be potent antimalarials [92] and validate farnesylation as essential in the malaria parasite. Drug development for antimalarials is taking a 'piggy-back' approach since the concentrations needed to inhibit parasites are significantly lower than that of mammalian cells [89].

\subsection{Palmitoylation}

Palmitoylation is the covalent attachment of fatty acids to cysteine residues of proteins, often giving soluble proteins (or proteins with weak membrane avidity) a hydrophobic membrane anchor [93]. In P. falciparum, a $45 \mathrm{kDa}$ gliding-associated protein (GAP45) was found to be both palmitoylated and N-myristoylated [94]. It is hypothesized that GAP45 may play a role in binding acto-myosin motors to the outer face of the inner membrane complex, which is implicated as the underlying force driving both gliding motility and host cell invasion in Plasmodium merozoites.

\section{Ubiquitination}

Ubiquitin is a highly conserved 76 amino acid peptide found in eukaryotic organisms. Beyond the more familiar association with protein degradation, the modification of proteins by ubiquitin conjugation is known to serve as a regulatory signal for cell proliferation, cell-stress response, transcription, cell death, DNA repair, intracellular trafficking, endocytosis and signal transduction [95]. The reversible conjugation of ubiquitin to the lysine residues in target proteins is controlled by a series of enzymes: ubiquitin activating enzymes (E1), ubiquitin-conjugating enzymes (E2), and ubiquitin ligases (E3) [96]. Ubiquitin is activated by E1 and transferred to E2. Then, ubiquitin is either transferred to a monomeric E3 that catalyzes ubiquitination of the target substrate or ubiquitinated E2 forms a complex with the E3 to catalyze ubiquitination of the substrate. Deubiquitinating enzymes (DUBs) serve to reverse ubiquitin-conjugation by removing ubiquitin from substrate proteins and also help to replenish the free ubiquitin pool.

Diverse forms of ubiquitin modifications have been reported, each potentially mediating a specific function. K48-linked polyubiquitin chains to substrates often serve as signals for targeted protein degradation via the ubiquitin/proteasome system [97]. In Plasmodium, several studies have validated the essentiality of the proteasome and protein turnover in regulating the cell cycle progression. A collection of proteasome inhibitors has shown promising results in impeding the parasites [98-103].

Apart from protein degradation, poly-ubiquitination via K63linkages seems to play important roles in DNA damage tolerances, endocytosis, ribosomal protein synthesis, and inflammatory response [104]. In addition to poly-ubiquitination, proteins can either be mono-ubiquitinated, which is the attachment of a single ubiquitin to a protein, or multi-ubiquitinated, which is the 
attachment of individual ubiquitin to a substrate at multiple sites. Both mono- and multi-ubiquitination are reported to have nonproteolytic roles such as endocytosis [105] and DNA repair [106]. In the following sections, we briefly describe what has been reported so far concerning ubiquitination in Plasmodium.

\subsection{Ubiquitin and ubiquitin-like proteins}

The P. falciparum poly-ubiquitin gene, PfpUB (PFL0585w) is present as a single-copy on chromosome 12 with five tandem repeats of the ubiquitin open reading frame [107]. Translation of PfpUB comprises of five ubiquitin monomers that have sequence identities of no less than $94 \%$ to that of other eukaryotic species. RT-PCR and northern analysis revealed that steady-state transcript levels of PfpUB are expressed at all stages of the intraerythrocytic cycles with significant increases at the late trophozoite and schizont stages. Under heat shock, polypeptide levels of PfpUB and ubiquitinated adducts showed dramatic increases without a significant increase in steady-state transcript levels. This observation suggests that the heat shock response appears to be maintained at the level of translation [107].

Two additional ubiquitin moieties, $\mathrm{Ub}_{\mathrm{S} 27 \mathrm{a}}$ and $\mathrm{Ub}_{\mathrm{L} 40}$, fused to the ribosomal proteins L40 (PF13_0346) and S27a (PF14_0027) have also been identified in the $P$. falciparum genome $[108,109]$. Expression data indicate that these ubiquitin genes are expressed throughout the P. falciparum life cycle [5,7]. Interestingly, though the $P f \mathrm{Ub}_{\mathrm{L} 40}$ shows high protein sequence fidelity with other eukaryotic species, $P f \mathrm{Ub}_{\mathrm{S} 27 \mathrm{a}}$ harbors significant divergences within the ubiquitin domain [109].

In addition to ubiquitin, ubiquitin-like proteins (UBLps) have been identified as modifiers of cellular-processes. Though a number of UBLps (ISG15, FAT10, UFM1, FUB1) that are typical in higher eukaryotes were not found in Plasmodium, gene expression data suggests that SUMO, NEDD8, HUB1, URM1 and ATG8 are expressed at all life-cycle stages [108,110].

Recently, Issar et al. (2008) [111] were the first to investigate and characterize SUMO within $P$. falciparum. Amino acid sequence comparisons revealed that $P$. falciparum gene PFE0285c (PfSUMO) has significant sequence homology to that of known SUMO orthologs from other eukaryotic organisms such as yeast, human, mouse and Saccharomyces pombe, while immunoblot analysis confirmed the presence of SUMO in P. falciparum. In addition, enzyme homology searches have identified $P$. falciparum orthologs of all the necessary members of the SUMO pathway. Using LC-MS/MS analysis, more than 20 putative SUMO substrates of $P$. falciparum proteins were identified. These protein substrates varied from histones to transcription factors to RNA helicases, which implicates a wideranging regulatory scope of SUMO. Immunofluorescence assays indicate that PfSUMO localizes to distinctive subcellular compartments within the P. falciparum and also in the host cell cytoplasm within the parasite-derived structures called Maurer's clefts.

\subsection{Ubiquitin enzymes}

Computational studies have identified over a hundred proteins predicted to be involved in the reversible conjugation of ubiquitin or ubiquitin-like proteins in P. falciparum alone [108,110].

\subsubsection{Ubiquitin activating enzymes (E1)}

Eight putative E1 have been identified in the parasite genome [108]. While primary sequence identity has been observed in the core ubiquitin activating enzyme domain, sequences outside of this core diverge rapidly as the functional requirements for these E1 enzymes change to specifically interact with their respective E2 conjugating enzymes. Sequence analysis indicates the existence of Plasmodium E1 paralogs for UBA1 and UBA1-like proteins, and
UBA2, UBA3, UBA4, ATG7 proteins, which mediate the activation of ubiquitin-like proteins SUMO, NEDD8, URM1, and ATG8, respectively.

\subsubsection{Ubiquitin conjugating enzymes (E2)}

Fourteen putative E2 paralogs were found in P. falciparum [108]. They exhibited extensive conservation with other eukaryotic E2 proteins. Gene expression data for nine of the fourteen Plasmodium E2s reveal a diverse pattern of steady-state mRNA at different stages of the intraerythrocytic cycle, suggesting the existence of a temporal profile of delivering ubiquitin or UbLps to different E3s, indicating a potential additional level of temporal control in ubiquitination during the parasite's life cycle.

Recently, a Pf homolog (PfUBC13) of the E2 ubiquitinconjugating enzyme 13 (UBC13) was characterized and found to be a substrate of the Pf protein kinase PfPK9 [112]. Reverse-phase HPLC and in vitro ubiquitination assay show that PfPK9 phosphorylates PfUBC13 at S106 and suppresses ubiquitin conjugating activity. Though the physiological role of PfUBC13 is unknown, the highlyconserved UBC13 (coupled with an ubiquitin E2-variant protein) assembles K63-linked ubiquitin chains [113], which mediate nonproteolytic pathways [114]. UBC13's conjugating activity regulates various cellular processes such as DNA repair [115], tumor suppressor p53 activity [116], and mitotic progression [117].

\subsubsection{Ubiquitin ligating enzymes (E3)}

Though Plasmodium E1 and E2 enzymes exhibited strong conserved homology with other E1 and E2 enzymes from other eukaryotes, Plasmodium E3 ligases were found to be highly divergent and the most abundant. Within the 54 putative E3 ligases identified, all superfamilies (HECT, RING, U-box, and cullin) of E3 ligases are represented within $P$. falciparum with E3 RING finger proteins making up the majority of the Plasmodium E3 ligases [108].

Functional annotation analysis reveals that these Plasmodium ligases have a wide array of potential roles including cell cycle regulation, trafficking, DNA repair, chromatin structure, and mRNA transport. However several of these proteins seem to be specific to the Apicomplexa phylum. While the functional analysis of these parasite-specific putative E3s will need to be further validated in vitro and in vivo, two selected E3 ligases seem to be essential to the parasite erythrocytic cycle and have already shown in vitro ubiquitination activity validating further the importance of this pathway in parasite development (Chung and Le Roch, unpublished data).

\subsubsection{Deubiquitinating enzymes}

While ubiquitin ligases catalyze the attachment of ubiquitin and UbLs, DUBs hydrolyze ubiquitin and UbLps [118]. Depending on the computational tools employed, 18 or 29 Plasmodium DUBs were found $[108,110]$. Five distinct gene families were identified: the ubiquitin C-terminal hydrolases (UCHs); the ubiquitin-specific peptidases (USPs/UBPs); the ovarian tumor (OTU) domain proteins; the Josephin or Machado-Joseph disease (MJD) proteins and the JAMM (Jab1/MPN domain-associated metalloisopeptidase) domain proteins. In addition, DUBs for UbLps including SUMO, ATG8, and NEDD8 have also been identified.

PfUCH54 was the first DUB characterized in P. falciparum [119]. Using electrophilic probes that detect enzymes capable of removing ubiquitin and other ubiquitin-like proteins, PfUCH54 was found to possess both deubiquitination and deneddylation activity. Using known active site residues and crystal structure of homologous DUBs, PfUCH54 was found to have high homology to UCHL3 [119], an enzyme that has been reported to also have dual deubiquitinating and deneddylating activity [120]. Though the function of PfUCH54 is not known, mouse UCHL3 is required to maintain a stable apical membrane epithelial sodium channel, facilitating the dynamic recycling of sodium channels at the apical surface [121]. 
Though functional analysis studies will need to further validate the roles of ubiquitination pathways in Plasmodium, E3 ligases and DUBs may represent a good target for new therapeutic interventions due to their diversity and potential involvement in parasite-specific pathways.

\section{Protein cleavage and processing}

Proteases are major virulence factors in parasitic diseases as largely reviewed by [122] and [123]. Five main classes of proteases have been identified: (1) cysteine proteases, (2) serine proteases, (3) threonine proteases, (4) aspartic proteases, and (5) metalloproteases. A computational analysis identified 92 proteases in the genome of $P$. falciparum, 83 of them being transcribed during the erythrocytic cell cycle and 67 being translated during the parasite's life cycle [124]. Proteases are commonly involved in a wide array of biological processes such as lysosomal proteolysis, precursor protein processing or trafficking.

In Plasmodium, trafficking is a vital biological process, especially with regards to targeting proteins to the apicoplast. Trafficking pathways leading to the apicoplast have not yet been elucidated but are known to involve the presence of both a signal peptide and a transit peptide that are processed along the pathway [125]. Wu et al. identified a serine protease Signal Peptidase 1 (SP1, PF13_0118) that could be responsible for the cleavage of signal peptides [124]. In addition, metalloprotease falcilysin (PF13_0322 in P. falciparum) [126] has been recently implicated in transit peptide cleavage [127].

Another important parasite-specific pathway is the PEXELmediated pathway that targets parasite proteins to the surface of infected erythrocytes. This pathway is thought to promote parasite evasion from the host immune system [128]. Chang et al. (2008) demonstrated that exported proteins are processed at their N-terminal end [129]. This processing involves acetylation and cleavage of the PEXEL motif in the endoplasmic reticulum. The authors suggest that this N-terminal processing may be more generally utilized for many exported soluble proteins. However, the protease responsible for such cleavage remains to be identified.

In Plasmodium, various proteases play key roles in hemoglobin degradation, egress and invasion during the parasite erythrocytic cycle. The roles of such proteases were usually determined from inhibitor studies, which emphasize the potential to target such enzymes by anti-malarial drugs.

\subsection{Hemoglobin degradation}

The degradation of hemoglobin involves various proteases called hemoglobinases [130] and provides the essential amino acids that are taken up by the parasite $[122,131,132]$.

The cysteine proteases falcipain-2 (PF11_0165) and falcipain3 (PF11_0162) are known to play a role in the early steps of hemoglobin degradation within the parasite food vacuole (see [133] for a review). In addition to these cysteine proteases, degradation of hemoglobin seems to involve metallo (falcilysin) and aspartic proteases such as plasmepsins [131]. Four plasmepsins are present and active in the food vacuole of $P$. falciparum, plasmepsin I (PF14_0076), II (PF14_0077), IV (PF14_0075) and a histo-aspartic protease (HAP, PF14_0078) [134-136]. It was postulated that plasmepsins I and II are matured and released in the food vacuole by protein cleavage $[134,137]$. A recent study demonstrated that falcipain-2 and falcipain-3 are responsible for plasmepsins preprocessing and that auto-processing can occur when falcipain activities are inhibited, providing an alternative pathway to activate plasmepsins [138].

\subsection{Parasite egress}

Parasite proteases are also known to trigger the degradation of parasite and host membranes, leading to the egress of infectious parasites. The role of these proteases in cell egress has been recently reviewed [139]. Briefly, the proteases implicated in parasite egress are falcipain II, plasmepsin II and putative papain-like SERA proteases. SERA proteins are a family of nine members, which are activated by a subtilisin-like serine protease SUB1 (PFE0370c). Among them are SERA-4 (PFB0345c), SERA-5 (PFB0340c, [140]) and SERA-6 (PFB0335c), which are essential proteins that are expressed in the parasitophorous vacuole of the late trophozoite and schizont stage (erythrocytic cycle) [141]. Additionally, SERA8 (PFB0325c), another member of the SERA protein family, is essential for sporozoite release from oocytes (mosquito stage) [142].

The involvement of the subtilisin-family serine protease PfSUB1 and the cysteine protease dipeptidyl peptidase 3 (DPAP3, PFD0230c) as primary regulators of parasite egress have been recently evidenced using serine and cysteine protease inhibitors [143]. Just prior to egress, the essential serine protease PfSUB1 is discharged from the exonemes into the parasitophorous vacuole space [144]. Inhibition of both DPAP3 and PfSUB1 blocks the processing of the serine repeat antigen protein SERA-5, which correlates with the inhibition of membrane rupture. In Plasmodium, two other subtilisin serine proteases of unknown function can be found: PfSUB2 (PF11_0381) and PfSUB3 (PFE0355c) (reviewed in [145]). PfSUB2 is believed to play an important role in the erythrocytic cycle while PfSUB3 appears to be more ubiquitous as it is expressed during the asexual blood stage, in gametocytes and in sporozoites [6].

\subsection{Parasite invasion}

The critical role of proteases in merozoite invasion of erythrocytes has been largely studied and reviewed [39,146]. Briefly, invasion involves contact, interaction and junction between the merozoite and the red blood cell surface via adhesins and various GPI-anchored proteins, such as PfAMA-1 and MSPs followed by the active entry of the parasite within the host. In order for invasion to be completed, these interactions are interrupted by the shedding of the protein coat covering the merozoite surface made of various MSPs and adhesins. The proteases involved in such removal are called sheddases. For example, the adhesins Duffy binding ligand erythrocyte-binding antigen (DBL-EBP) 175 (EBA175, MAL7P1.176) is shed from the merozoite at around the point of invasion by the rhomboid protease PfROM4 (PFE0340c) [147]. Rhomboid proteases are ubiquitous intramembrane serine proteases (see [148-150] for an extensive description of the different types of rhomboid proteases). Also, sporozoite invasion of hepatocytes is reported to be mediated by the shedding of PfAMA-1 and the thrombospondin-related adhesive protein (TRAP) by a serine protease [151].

Double cleavage of MSPs is required for invasion and probably involves serine proteases 9 See Harris, Yeoh et al. (2005) [152] for further details 0 . Very recently, it was suggested that MSP-1, MSP6 and MSP-7 undergo proteolytic maturation catalyzed by PfSUB1 before egress, maturation that is essential for further processing of MSPs involved in invasion [153].

A role of cysteine proteases (falcipain) in erythrocyte invasion has also been proposed but remains elusive. Inhibitors of falcipain1 (PF14_0553) block invasion of host red blood cells [154] whereas parasites with a disrupted falcipain-1 gene were not affected in terms of asexual growth [155]. More recently, the presence of an endogenous cysteine protease inhibitor in $P f$, falstatin, has been identified [156]. The presence of such an endogenous inhibitor may 
be another level of proteolytic control of certain parasite/host proteases in order to facilitate erythrocyte invasion.

Proteolytic processing is finally involved in the maturation of proteins secreted by the merozoite-specific organelles, rhoptries. Rhoptry-associated proteins (RAP) are believed to play a role in invasion and are activated upon proteolytic cleavage. For example, the rhoptry-associated protein RAP-1 is maturated in vivo by multiple processing steps [157-159].

\section{Concluding remarks}

In addition to the PTMs presented above, there are several other PTMs in Plasmodium that are being investigated but, due to spaceconstraints, are unable to be fully expanded upon in this review. However, we would like to briefly mention a few. For example, a Plasmodium cathepsin-C-like protein is reported to be modified via O-sulfonation [160]. Also, polyglutamylation of tubulin was found in the microtubule organizing centers and post-mitotic microtubular structures of Plasmodium [161]. Lastly, several chaperone proteins, involved in the proper folding of proteins, have been described in Plasmodium and are reported to be involved in roles such as trafficking [162-165].

Today, transcriptional studies make up a significant amount of publications that are dedicated to understanding mechanisms regulating the Plasmodium developmental cycle. However, recent evidences suggest that Plasmodium may not follow the classical transcriptional model and may have rigid transcription machinery, which may indicate the need to reallocate investigative efforts into other fields in order to better understand the parasite's life-cycle regulation. With the exception of phosphorylation/dephosphorylation, post-translational modifications in Plasmodium have been understudied and are largely overshadowed by the classical view that proteins are mainly regulated at the transcriptional level. With further investigation, post-translational regulation may reveal to be a bigger factor in parasite development than previously thought.

For example, though it is apparent that proteases are necessary to destabilize host cell membranes during invasion and egress, the mechanisms of how these proteases are activated and tightly controlled temporally are yet unclear. However, there are increasing reports that PTMs may play a major role in both malarial invasion and egress. As already described above, it is suggested that additional proteases, such as SUB proteases, may act as regulators of egress by processing, and thereby activating, distinct effector proteins or signal transduction pathways $[139,144]$. In addition, it is reported that $P f$ protein kinases, such as CDPK, may also be involved in regulating invasion and egress [19].

Besides having a major regulatory role within the parasite, PTMs may also play key roles outside the parasite by manipulating the host's signaling pathways thereby usurping normal cellular processes for survival and escape from immune responses. Currently, there are an increasing number of reports that show PTMs to play an integral role in host-pathogen interactions, or cross-talk, in bacteria, viruses and protozoa [166-168]. For example, it has been shown that host organisms employ a wide range of posttranslational modifications to initiate their immune responses in order to avoid invasion by pathogens. For instance, host cells use ubiquitination in defense strategies as a way to degrade parasitic proteins and also to activate inflammatory and anti-apoptotic genes in a non-degradative fashion [169]. As a countermeasure, it has been shown that pathogens are able to avoid and exploit these ubiquitination defense strategies by secreting proteins of their own that either deubiquitinate or inhibit the host ubiquitinating enzymes [169,170]. It is also reported that bacterial pathogens are able to provoke histone modifications (via acetylation and phosphorylation) and chromatin remodeling in host cells, thereby manipulating the host's transcriptional programming and diminish the host innate immune response [167]. The utilization of PTMs within host-pathogen interactions for the purposes of pathogenic growth and immune evasion is an emerging field, which may prove to be both widespread and diverse in the mechanisms at work.

The utilization of PTMs to manipulate host cell signaling and immune response may also be true in Plasmodium. In P. falciparum, it is reported that kinases and phosphatases were found among the $320+$ proteins predicted to be secreted from the parasite [48]. More recently, over 30 proteins have been validated to be secreted from the Pf, of which 27 proteins are novel extracellular proteins [171]. Several post-translational modifiers, such as kinases, phosphatases, and proteases, were confirmed to be among the secreted proteins. Furthermore, preliminary functional analysis suggests that these secreted proteins are possibly involved in immune evasion and signaling [171].

Our current understanding of the roles and extent of PTMs within Plasmodium is still greatly limited due to the relative novelty and inherent challenges of this particular field. More genomewide approaches, along with their proper biological validation, will provide significant advances in filling the gaps of our present understanding of the regulatory mechanisms driving this deadly parasite. Though there is still much more to uncover, current reports collectively show that Plasmodium PTMs have vital roles in all aspects of the parasites' life cycle, including host-pathogen interactions. Because of the numerous types and virtually incalculable combinations of PTMs, the possibilities of regulation at the post-translational level are vast. In addition to being vitally essential, many Plasmodium PTM proteins are both highly divergent and specific to the parasite, making Plasmodium PTM proteins excellent candidates for drug targeting. Thus, Plasmodium PTMs may open new venues for drug discovery and may prove to be more significant in the regulation of this deadly parasite than previously acknowledged.

\section{References}

[1] Miller LH, Greenwood B. Malaria-a shadow over Africa. Science 2002;298(5591):121-2.

[2] Breman JG, Egan A, Keusch GT. The intolerable burden of malaria: a new look at the numbers. Am J Trop Med Hyg 2001;64(1-2 Suppl.):iv-vii.

[3] Guerra CA, Gikandi PW, Tatem AJ, Noor AM, Smith DL, Hay SI, et al. The limits and intensity of Plasmodium falciparum transmission: implications for malaria control and elimination worldwide. PLoS Med 2008;5(2):e38.

[4] Gardner MJ, Hall N, Fung E, White O, Berriman M, Hyman RW, et al. Genome sequence of the human malaria parasite Plasmodium falciparum. Nature 2002;419(6906):498-511.

[5] Bozdech Z, Llinas M, Pulliam BL, Wong ED, Zhu J, DeRisi JL. The transcriptome of the intraerythrocytic developmental cycle of Plasmodium falciparum. PLoS Biol 2003;1(1):E5.

[6] Le Roch KG, Zhou Y, Blair PL, Grainger M, Moch JK, Haynes JD, et al. Discovery of gene function by expression profiling of the malaria parasite life cycle. Science 2003;301(5639):1503-8.

[7] Le Roch KG, Johnson JR, Florens L, Zhou Y, Santrosyan A, Grainger M, et al. Global analysis of transcript and protein levels across the Plasmodium falciparum life cycle. Genome Res 2004;14(11):2308-18.

[8] Coulson RM, Hall N, Ouzounis CA. Comparative genomics of transcriptional control in the human malaria parasite Plasmodium falciparum. Genome Res 2004;14(8):1548-54.

[9] Le Roch KG, Johnson JR, Ahiboh H, Chung DW, Prudhomme J, Plouffe D, et al. A systematic approach to understand the mechanism of action of the bisthiazolium compound T4 on the human malaria parasite, Plasmodium falciparum. BMC Genomics 2008;9:513.

[10] Ganesan K, Ponmee N, Jiang L, Fowble JW, White J, Kamchonwongpaisan $S$, et al. A Genetically Hard-Wired Metabolic Transcriptome in Plasmodium falciparum Fails to Mount Protective Responses to Lethal Antifolates. PLoS Pathogens 2008;4(11):e1000214.

[11] Hoffman MD, Sniatynski MJ, Kast J. Current approaches for global posttranslational modification discovery and mass spectrometric analysis. Anal Chim Acta 2008;627(1):50-61.

[12] Clark RS, Bayir H, Jenkins LW. Posttranslational protein modifications. Crit Care Med 2005;33(12 Suppl.):S407-9. 
[13] Jensen ON. Modification-specific proteomics: characterization of posttranslational modifications by mass spectrometry. Curr Opin Chem Biol 2004;8(1):33-41.

[14] Reinders J, Sickmann A. State-of-the-art in phosphoproteomics. Proteomics 2005;5(16):4052-61.

[15] Sickmann A, Meyer HE. Phosphoamino acid analysis. Proteomics 2001;1(2):200-6.

[16] Bollen M. Combinatorial control of protein phosphatase-1. Trends Biochem Sci $2001 ; 26(7): 426-31$

[17] Dorin D, Le Roch K, Sallicandro P, Alano P, Parzy D, Poullet P, et al. Pfnek-1, a NIMA-related kinase from the human malaria parasite Plasmodium falciparum Biochemical properties and possible involvement in MAPK regulation. Eur J Biochem 2001;268(9):2600-8.

[18] McRobert L, Taylor CJ, Deng W, Fivelman QL, Cummings RM, Polley SD, et al. Gametogenesis in malaria parasites is mediated by the cGMP-dependent protein kinase. PLoS Biol 2008;6(6):e139.

[19] Kato N, Sakata T, Breton G, Le Roch KG, Nagle A, Andersen C, et al. Gene expression signatures and small-molecule compounds link a protein kinase to Plasmodium falciparum motility. Nat Chem Biol 2008;4(6):347-56.

[20] Knockaert M, Gray N, Damiens E, Chang YT, Grellier P, Grant K, et al. Intracellular targets of cyclin-dependent kinase inhibitors: identification by affinity chromatography using immobilised inhibitors. Chem Biol 2000;7(6):411-22.

[21] Anamika, Srinivasan N, Krupa A. A genomic perspective of protein kinases in Plasmodium falciparum. Proteins 2005;58(1):180-9.

[22] Ward P, Equinet L, Packer J, Doerig C. Protein kinases of the human malaria parasite Plasmodium falciparum: the kinome of a divergent eukaryote. BMC Genomics 2004;5(1):79.

[23] Schneider AG, Mercereau-Puijalon O. A new Apicomplexa-specific protein kinase family: multiple members in Plasmodium falciparum, all with an export signature. BMC Genomics 2005;6(1):30.

[24] Zhang XS, Choi JH. Molecular evolution of calmodulin-like domain protein kinases (CDPKs) in plants and protists. J Mol Evol 2001;53(3):214-24.

[25] Merckx A, Le Roch K, Nivez MP, Dorin D, Alano P, Gutierrez GJ, et al. Identification and initial characterization of three novel cyclin-related proteins of the human malaria parasite Plasmodium falciparum. J Biol Chem 2003;278(41):39839-50.

[26] Li Z, Le Roch K, Geyer JA, Woodard CL, Prigge ST, Koh J, et al. Influence of human $\mathrm{p} 16$ (INK4) and p21(CIP1) on the in vitro activity of recombinant Plasmodium falciparum cyclin-dependent protein kinases. Biochem Biophys Res Commun $2001 ; 288(5): 1207-11$.

[27] Le Roch K, Sestier C, Dorin D, Waters N, Kappes B, Chakrabarti D, et al. Activation of a Plasmodium falciparum cdc2-related kinase by heterologous p25 and cyclin $\mathrm{H}$. Functional characterization of a P. falciparum cyclin homologue. J Biol Chem 2000;275(12):8952-8.

[28] Graeser R, Wernli B, Franklin RM, Kappes B. Plasmodium falciparum protein kinase 5 and the malarial nuclear division cycles. Mol Biochem Parasitol 1996;82(1):37-49.

[29] Holton S, Merckx A, Burgess D, Doerig C, Noble M, Endicott J. Structures of P. falciparum PfPK5 test the CDK regulation paradigm and suggest mechanisms of small molecule inhibition. Structure 2003;11(11):1329-37.

[30] Schrevel J, Asfaux-Foucher G, Bafort JM. Ultrastructural study of multiple mitoses during sporogony of Plasmodium b. berghei. J Ultrastruct Res 1977;59(3):332-50.

[31] Dorin-Semblat D, Sicard A, Doerig C, Ranford-Cartwright L, Doerig C. Disruption of the PfPK7 gene impairs schizogony and sporogony in the human malaria parasite Plasmodium falciparum. Eukaryot Cell 2008;7(2):279-85.

[32] Raman M, Chen W, Cobb MH. Differential regulation and properties of MAPKs. Oncogene 2007;26(22):3100-12.

[33] Dorin-Semblat D, Quashie N, Halbert J, Sicard A, Doerig C, Peat E, et al. Functional characterization of both MAP kinases of the human malaria parasite Plasmodium falciparum by reverse genetics. Mol Microbiol 2007;65(5):1170-80.

[34] Tewari R, Dorin D, Moon R, Doerig C, Billker O. An atypical mitogen-activated protein kinase controls cytokinesis and flagellar motility during male gamete formation in a malaria parasite. Mol Microbiol 2005;58(5):1253-63.

[35] Billker O, Dechamps S, Tewari R, Wenig G, Franke-Fayard B, Brinkmann V. Calcium and a calcium-dependent protein kinase regulate gamete formation and mosquito transmission in a malaria parasite. Cell 2004;117(4):503-14.

[36] Siden-Kiamos I, Ecker A, Nyback S, Louis C, Sinden RE, Billker O. Plasmodium berghei calcium-dependent protein kinase 3 is required for ookinete gliding motility and mosquito midgut invasion. Mol Microbiol 2006;60(6):1355-63.

[37] Ishino T, Orito Y, Chinzei Y, Yuda M. A calcium-dependent protein kinase regulates Plasmodium ookinete access to the midgut epithelial cell. Mol Microbiol 2006;59(4):1175-84.

[38] Reininger L, Billker O, Tewari R, Mukhopadhyay A, Fennell C, Dorin-Semblat D, et al. A NIMA-related protein kinase is essential for completion of the sexual cycle of malaria parasites. J Biol Chem 2005;280(36):31957-64.

[39] Cowman AF, Crabb BS. Invasion of red blood cells by malaria parasites. Cell 2006;124(4):755-66.

[40] Moskes C, Burghaus PA, Wernli B, Sauder U, Durrenberger M, Kappes B. Export of Plasmodium falciparum calcium-dependent protein kinase 1 to the parasitophorous vacuole is dependent on three $\mathrm{N}$-terminal membrane anchor motifs. Mol Microbiol 2004;54(3):676-91.

[41] Kumar A, Vaid A, Syin C, Sharma P. PfPKB, a novel protein kinase B-like enzyme from Plasmodium falciparum: I. Identification, characterization, and possible role in parasite development. J Biol Chem 2004;279(23):24255-64.
[42] Vaid A, Sharma P. PfPKB, a protein kinase B-like enzyme from Plasmodium falciparum: II. Identification of calcium/calmodulin as its upstream activator and dissection of a novel signaling pathway. J Biol Chem 2006;281(37):27126-33.

[43] Vaid A, Thomas DC, Sharma P. Role of Ca2+/calmodulin-PfPKB signaling pathway in erythrocyte invasion by Plasmodium falciparum. J Biol Chem 2008;283(9):5589-97.

[44] Merckx A, Bouyer G, Thomas SL, Langsley G, Egee S. Anion channels in Plasmodium-falciparum-infected erythrocytes and protein kinase A. Trends Parasitol 2009;25(3):139-44.

[45] Merckx A, Nivez MP, Bouyer G, Alano P, Langsley G, Deitsch K, et al. Plasmodium falciparum regulatory subunit of cAMP-dependent PKA and anion channel conductance. PLoS Pathog 2008;4(2):e19.

[46] Nunes MC, Goldring JP, Doerig C, Scherf A. A novel protein kinase family in Plasmodium falciparum is differentially transcribed and secreted to various cellular compartments of the host cell. Mol Microbiol 2007;63(2):391-403.

[47] Marti M, Good RT, Rug M, Knuepfer E, Cowman AF. Targeting malaria virulence and remodeling proteins to the host erythrocyte. Science 2004;306(5703):1930-3.

[48] Hiller NL, Bhattacharjee S, van Ooij C, Liolios K, Harrison T, Lopez-Estrano $\mathrm{C}$, et al. A host-targeting signal in virulence proteins reveals a secretome in malarial infection. Science 2004;306(5703):1934-7.

[49] Wilkes JM, Doerig C. The protein-phosphatome of the human malaria parasite Plasmodium falciparum. BMC Genomics 2008;9:412.

[50] Li JL, Baker DA. A putative protein serine/threonine phosphatase from Plasmodium falciparum contains a large $\mathrm{N}$-terminal extension and five unique inserts in the catalytic domain. Mol Biochem Parasitol 1998;95(2):287-95.

[51] Mamoun CB, Sullivan Jr DJ, Banerjee R, Goldberg DE. Identification and characterization of an unusual double serine/threonine protein phosphatase $2 \mathrm{C}$ in the malaria parasite Plasmodium falciparum. J Biol Chem 1998;273(18):11241-7.

[52] Dobson S, May T, Berriman M, Del Vecchio C, Fairlamb AH, Chakrabarti D, et al. Characterization of protein Ser/Thr phosphatases of the malaria parasite. Plasmodium falciparum: inhibition of the parasitic calcineurin by cyclophilincyclosporin complex Mol Biochem Parasitol 1999;99(2):167-81.

[53] Ward GE, Fujioka H, Aikawa M, Miller LH. Staurosporine inhibits invasion of erythrocytes by malarial merozoites. Exp Parasitol 1994;79(3):480-7.

[54] Yokoyama D, Saito-Ito A, Asao N, Tanabe K, Yamamoto M, Matsumura T. Modulation of the growth of Plasmodium falciparum in vitro by protein serine/threonine phosphatase inhibitors. Biochem Biophys Res Commun 1998;247(1):18-23.

[55] Mamoun CB, Goldberg DE. Plasmodium protein phosphatase 2C dephosphorylates translation elongation factor 1beta and inhibits its PKC-mediated nucleotide exchange activity in vitro. Mol Microbiol 2001;39(4):973-81.

[56] Kumar R, Musiyenko A, Cioffi E, Oldenburg A, Adams B, Bitko V, et al. A zinc-binding dual-specificity YVH1 phosphatase in the malaria parasite, Plasmodium falciparum, and its interaction with the nuclear protein, pescadillo. Mol Biochem Parasitol 2004;133(2):297-310.

[57] Blisnick T, Vincensini L, Fall G, Braun-Breton C. Protein phosphatase 1 a Plasmodium falciparum essential enzyme, is exported to the host cell and implicated in the release of infectious merozoites. Cell Microbiol 2006;8(4):591-601.

[58] Rudolph J. Cdc25 phosphatases: structure, specificity, and mechanism. Biochemistry 2007;46(12):3595-604.

[59] Trinkle-Mulcahy L, Lamond AI. Mitotic phosphatases: no longer silent partners. Curr Opin Cell Biol 2006;18(6):623-31.

[60] Fauman EB, Saper MA. Structure and function of the protein tyrosine phosphatases. Trends Biochem Sci 1996;21(11):413-7.

[61] Pendyala PR, Ayong L, Eatrides J, Schreiber M, Pham C, Chakrabarti R, et al Characterization of a PRL protein tyrosine phosphatase from Plasmodium falciparum. Mol Biochem Parasitol 2008;158(1):1-10.

[62] Schmitz S, Grainger M, Howell S, Calder LJ, Gaeb M, Pinder JC, et al. Malaria parasite actin filaments are very short. J Mol Biol 2005;349(1):113-25.

[63] Miao J, Fan Q, Cui L, Li J, Li J, Cui L. The malaria parasite Plasmodium falciparum histones: organization, expression, and acetylation. Gene 2006;369:53-65.

[64] Cui L, Miao J, Furuya T, Li X, Su XZ, Cui L. PfGCN5-mediated histone H3 acetylation plays a key role in gene expression in Plasmodium falciparum. Eukaryot Cell 2007;6(7):1219-27.

[65] Fan Q, An L, Cui L. Plasmodium falciparum histone acetyltransferase, a yeast GCN5 homologue involved in chromatin remodeling. Eukaryot Cell 2004;3(2):264-76.

[66] Cui L, Miao J, Furuya T, Fan Q, Li X, Rathod PK, et al. Histone acetyltransferase inhibitor anacardic acid causes changes in global gene expression during in vitro Plasmodium falciparum development. Eukaryot Cell 2008;7(7):1200-10.

[67] Joshi MB, Lin DT, Chiang PH, Goldman ND, Fujioka H, Aikawa M, et al. Molecular cloning and nuclear localization of a histone deacetylase homologue in Plasmodium falciparum. Mol Biochem Parasitol 1999;99(1):11-9.

[68] Freitas-Junior LH, Hernandez-Rivas R, Ralph SA, Montiel-Condado D, Ruvalcaba-Salazar OK, Rojas-Meza AP, et al. Telomeric heterochromatin propagation and histone acetylation control mutually exclusive expression of antigenic variation genes in malaria parasites. Cell 2005;121(1):25-36.

[69] Andrews KT, Tran TN, Wheatley NC, Fairlie DP. Targeting histone deacetylase inhibitors for anti-malarial therapy. Curr Top Med Chem 2009;9(3):292-308.

[70] Dow GS, Chen Y, Andrews KT, Caridha D, Gerena L, Gettayacamin M, et al Antimalarial activity of phenylthiazolyl-bearing hydroxamate-based histone deacetylase inhibitors. Antimicrob Agents Chemother 2008;52(10):3467-77. 
[71] Lopez-Rubio JJ, Gontijo AM, Nunes MC, Issar N, Hernandez Rivas R, Scherf A. 5' flanking region of var genes nucleate histone modification patterns linked to phenotypic inheritance of virulence traits in malaria parasites. Mol Microbiol 2007;66(6):1296-305.

[72] Cui L, Fan Q Cui L, Miao J. Histone lysine methyltransferases and demethylases in Plasmodium falciparum. Int J Parasitol 2008;38(10):1083-97.

[73] Gowda DC, Gupta P, Davidson EA. Glycosylphosphatidylinositol anchors represent the major carbohydrate modification in proteins of intraerythrocytic stage Plasmodium falciparum. J Biol Chem 1997;272(10):6428-39.

[74] Haldar K, Samuel BU, Mohandas N, Harrison T, Hiller NL. Erythrocytic vacuolar rafts induced by malaria parasites. Curr Opin Hematol 2001;8(2):92-7.

[75] Naik RS, Branch OH, Woods AS, Vijaykumar M, Perkins DJ, Nahlen BL, et al. Glycosylphosphatidylinositol anchors of Plasmodium falciparum: molecular characterization and naturally elicited antibody response that may provide immunity to malaria pathogenesis. J Exp Med 2000;192(11):1563-76.

[76] Schofield L, Hackett F. Signal transduction in host cells by a glycosylphosphatidylinositol toxin of malaria parasites. J Exp Med 1993;177(1):14553.

[77] Patel SN, Lu Z, Ayi K, Serghides L, Gowda DC, Kain KC. Disruption of CD36 impairs cytokine response to Plasmodium falciparum glycosylphosphatidylinositol and confers susceptibility to severe and fatal malaria in vivo. J Immunol 2007;178(6):3954-61.

[78] Nasir ud D, Ahmad I, Hoessli DC, Walker-Nasir E, Choudhary MI. Glycosylphosphatidylinositol (GPI) anchored proteins of Plasmodium falciparum: Antigenic determinants and role of sugar moieties in the GPI anchor. Current Organic Chemistry 2007;11(7):609-18.

[79] Proellocks NI, Kovacevic S, Ferguson DJ, Kats LM, Morahan BJ, Black CG, et al. Plasmodium falciparum Pf34, a novel GPI-anchored rhoptry protein found in detergent-resistant microdomains. Int J Parasitol 2007;37(11):123341.

[80] Gilson PR, Nebl T, Vukcevic D, Moritz RL, Sargeant T, Speed TP, et al. Identification and stoichiometry of glycosylphosphatidylinositol-anchored membrane proteins of the human malaria parasite Plasmodium falciparum. Mol Cell Proteomics 2006;5(7):1286-99.

[81] Lim J, Gowda DC, Krishnegowda G, Luckhart S. Induction of nitric oxide synthase in Anopheles stephensi by Plasmodium falciparum: mechanism of signaling and the role of parasite glycosylphosphatidylinositols. Infect Immun 2005;73(5):2778-89.

[82] Akman-Anderson L, Olivier M, Luckhart S. Induction of nitric oxide synthase and activation of signaling proteins in Anopheles mosquitoes by the malaria pigment, hemozoin. Infect Immun 2007;75(8):4012-9.

[83] Arrighi RB, Debierre-Grockiego F, Schwarz RT, Faye I. The immunogenic properties of protozoan glycosylphosphatidylinositols in the mosquito Anopheles gambiae. Dev Comp Immunol 2009;33(2):216-23.

[84] Blanco AR, Paez A, Gerold P, Dearsly AL, Margos G, Schwarz RT, et al. The biosynthesis and post-translational modification of Pbs21 an ookinete-surface protein of Plasmodium berghei. Mol Biochem Parasitol 1999;98(2):163-73.

[85] del Carmen Rodriguez M, Gerold P, Dessens J, Kurtenbach K, Schwartz RT, Sinden RE, et al. Characterisation and expression of Pbs25, a sexual and sporogonic stage specific protein of Plasmodium berghei. Molecular and Biochemical Parasitology 2000;110(1):147-59.

[86] Baton LA, Ranford-Cartwright LC. Do malaria ookinete surface proteins P25 and P28 mediate parasite entry into mosquito midgut epithelial cells? Malar J 2005;4(1):15.

[87] Wang Q, Fujioka H, Nussenzweig V. Mutational analysis of the GPI-anchor addition sequence from the circumsporozoite protein of Plasmodium. Cell Microbiol 2005;7(11):1616-26.

[88] Chakrabarti D, Da Silva T, Barger J, Paquette S, Patel H, Patterson S, et al. Protein farnesyltransferase and protein prenylation in Plasmodium falciparum. J Biol Chem 2002;277(44):42066-73.

[89] Eastman RT, Buckner FS, Yokoyama K, Gelb MH, Van Voorhis WC. Thematic review series: lipid posttranslational modifications. Fighting parasitic disease by blocking protein farnesylation. J Lipid Res 2006;47(2):233-40.

[90] Rohrich RC, Englert N, Troschke K, Reichenberg A, Hintz M, Seeber F, et al. Reconstitution of an apicoplast-localised electron transfer pathway involved in the isoprenoid biosynthesis of Plasmodium falciparum. FEBS Lett 2005;579(28):6433-8.

[91] D’Alexandri FL, Kimura EA, Peres VJ, Katzin AM. Protein dolichylation in Plasmodium falciparum. FEBS Lett 2006;580(27):6343-8.

[92] Fletcher S, Cummings CG, Rivas K, Katt WP, Horney C, Buckner FS, et al. Potent, Plasmodium-selective farnesyltransferase inhibitors that arrest the growth of malaria parasites: structure-activity relationships of ethylenediamine-analogue scaffolds and homology model validation. J Med Chem 2008;51(17):5176-97.

[93] Baekkeskov S, Kanaani J. Palmitoylation cycles and regulation of protein function (Review). Mol Membr Biol 2009;26(1):42-54.

[94] Rees-Channer RR, Martin SR, Green JL, Bowyer PW, Grainger M, Molloy JE, et al. Dual acylation of the $45 \mathrm{kDa}$ gliding-associated protein (GAP45) in Plasmodium falciparum merozoites. Mol Biochem Parasitol 2006;149(1):113-6.

[95] Hershko A. Ciechanover A. The ubiquitin system. Annu Rev Biochem 1998;67:425-79.

[96] Laney JD, Hochstrasser M. Substrate targeting in the ubiquitin system. Cell 1999;97(4):427-30.

[97] Kerscher O, Felberbaum R, Hochstrasser M. Modification of proteins by ubiquitin and ubiquitin-like proteins. Annu Rev Cell Dev Biol 2006;22:159-80.
[98] Gantt SM, Myung JM, Briones MR, Li WD, Corey EJ, Omura S, et al. Proteasome inhibitors block development of Plasmodium spp. Antimicrob Agents Chemother 1998;42(10):2731-8.

[99] Lindenthal C, Weich N, Chia YS, Heussler V, Klinkert MQ. The proteasome inhibitor MLN-273 blocks exoerythrocytic and erythrocytic development of Plasmodium parasites. Parasitology 2005;131(Pt 1):37-44.

[100] Reynolds JM, El Bissati K, Brandenburg J, Gunzl A, Mamoun CB. Antimalarial activity of the anticancer and proteasome inhibitor bortezomib and its analog ZL3B. BMC Clin Pharmacol 2007;7:13.

[101] Mordmüller B, Fendel R, Kreidenweiss A, Gille C, Hurwitz R, Metzger WG, et al. Plasmodia express two threonine-peptidase complexes during asexual development. Molecular and Biochemical Parasitology 2006;148(1):7985.

[102] Prudhomme J, McDaniel E, Ponts N, Bertani Sp, Fenical W, Jensen P, et al Marine Actinomycetes: A New Source of Compounds against the Human Malaria Parasite. PLoS ONE 2008;3(6):e2335.

[103] Kreidenweiss A, Kremsner PG, Mordmuller B. Comprehensive study of proteasome inhibitors against Plasmodium falciparum laboratory strains and field isolates from Gabon. Malar J 2008;7:187.

[104] Mukhopadhyay D, Riezman H. Proteasome-independent functions of ubiquitin in endocytosis and signaling. Science 2007;315(5809):201-5.

[105] Hicke L. Protein regulation by monoubiquitin. Nat Rev Mol Cell Biol 2001;2(3):195-201.

[106] Hofmann K. Ubiquitin-binding domains and their role in the DNA damage response. DNA Repair, 2009.

[107] Horrocks P, Newbold CI. Intraerythrocytic polyubiquitin expression in Plasmodium falciparum is subjected to developmental and heat-shock control. Mol Biochem Parasitol 2000;105(1):115-25.

[108] Ponts N, Yang J, Chung D-WD, Prudhomme J, Girke T, Horrocks P, et al. Deciphering the Ubiquitin-Mediated Pathway in Apicomplexan Parasites: A Potential Strategy to Interfere with Parasite Virulence. PLoS ONE 2008;3(6):e2386.

[109] Catic A, Ploegh HL. Ubiquitin-conserved protein or selfish gene? Trends Biochem Sci 2005;30(11):600-4.

[110] Ponder EL, Bogyo M. Ubiquitin-like modifiers and their deconjugating enzymes in medically important parasitic protozoa. Eukaryot Cell 2007;6(11):1943-52.

[111] Issar N, Roux E, Mattei D, Scherf A. Identification of a novel post-translational modification in Plasmodium falciparum: protein sumoylation in different cellular compartments. Cell Microbiol 2008;10(10):1999-2011.

[112] Philip N, Haystead TA. Characterization of a UBC13 kinase in Plasmodium falciparum. Proc Natl Acad Sci U S A 2007;104(19):7845-50.

[113] Hofmann RM, Pickart CM. Noncanonical MMS2-encoded ubiquitinconjugating enzyme functions in assembly of novel polyubiquitin chains for DNA repair. Cell 1999;96(5):645-53.

[114] Pickart CM. Ubiquitin enters the new millennium. Mol Cell 2001;8(3):499-504.

[115] Brusky J, Zhu Y, Xiao W. UBC13, a DNA-damage-inducible gene, is a member of the error-free postreplication repair pathway in Saccharomyces cerevisiae. Curr Genet 2000;37(3):168-74.

[116] Laine A, Topisirovic I, Zhai D, Reed JC, Borden KL, Ronai Z. Regulation of p53 localization and activity by Ubc13. Mol Cell Biol 2006;26(23):8901-13.

[117] Bothos J, Summers MK, Venere M, Scolnick DM, Halazonetis TD. The Chfr mitotic checkpoint protein functions with Ubc13-Mms2 to form Lys63-linked polyubiquitin chains. Oncogene 2003;22(46):7101-7.

[118] Singhal S, Taylor MC, Baker RT. Deubiquitylating enzymes and disease. BMC Biochem 2008;9 Suppl. 1:S3.

[119] Artavanis-Tsakonas K, Misaghi S, Comeaux CA, Catic A, Spooner E, Duraisingh MT, et al. Identification by functional proteomics of a deubiquitinating/deNeddylating enzyme in Plasmodium falciparum. Mol Microbiol 2006;61(5):1187-95.

[120] Wada H, Kito K, Caskey LS, Yeh ET, Kamitani T. Cleavage of the C-terminus of NEDD8 by UCH-L3. Biochem Biophys Res Commun 1998;251(3):68892.

[121] Butterworth MB, Edinger RS, Ovaa H, Burg D, Johnson JP, Frizzell RA. The deubiquitinating enzyme UCH-L3 regulates the apical membrane recycling of the epithelial sodium channel. J Biol Chem 2007;282(52):37885-93.

[122] McKerrow JH, Rosenthal PJ, Swenerton R, Doyle P. Development of protease inhibitors for protozoan infections. Curr Opin Infect Dis 2008;21(6):668-72.

[123] Armstrong PB. Proteases and protease inhibitors: a balance of activities in host-pathogen interaction. Immunobiology 2006;211(4):263-81.

[124] Wu Y, Wang X, Liu X, Wang Y. Data-mining approaches reveal hidden families of proteases in the genome of malaria parasite. Genome Res 2003;13(4):601-16.

[125] Waller RF, Reed MB, Cowman AF, McFadden GI. Protein trafficking to the plastid of Plasmodium falciparum is via the secretory pathway. Embo J 2000;19(8):1794-802.

[126] Eggleson KK, Duffin KL, Goldberg DE. Identification and characterization of falcilysin, a metallopeptidase involved in hemoglobin catabolism within the malaria parasite Plasmodium falciparum. J Biol Chem 1999;274(45):32411-7.

[127] Ponpuak M, Klemba M, Park M, Gluzman IY, Lamppa GK, Goldberg DE. A role for falcilysin in transit peptide degradation in the Plasmodium falciparum apicoplast. Mol Microbiol 2007;63(2):314-34.

[128] Craig A, Scherf A. Molecules on the surface of the Plasmodium falciparum infected erythrocyte and their role in malaria pathogenesis and immune evasion. Mol Biochem Parasitol 2001;115(2):129-43. 
[129] Chang HH, Falick AM, Carlton PM, Sedat JW, DeRisi JL, Marletta MA. N-terminal processing of proteins exported by malaria parasites. Mol Biochem Parasitol 2008;160(2):107-15.

[130] Goldberg DE. Hemoglobin degradation. Curr Top Microbiol Immunol 2005;295:275-91.

[131] Francis SE, Banerjee R, Goldberg DE. Biosynthesis and maturation of the malaria aspartic hemoglobinases plasmepsins I and II. J Biol Chem 1997;272(23):14961-8

[132] Lew VL, Tiffert T, Ginsburg H. Excess hemoglobin digestion and the osmotic stability of Plasmodium falciparum-infected red blood cells. Blood 2003;101(10):4189-94.

[133] Rosenthal PJ. Cysteine proteases of malaria parasites. Int J Parasitol 2004;34(13-14):1489-99.

[134] Banerjee R, Liu J, Beatty W, Pelosof L, Klemba M, Goldberg DE. Four plasmepsins are active in the Plasmodium falciparum food vacuole, including a protease with an active-site histidine. Proc Natl Acad Sci U S A 2002;99(2):990-5.

[135] Coombs GH, Goldberg DE, Klemba M, Berry C, Kay J, Mottram JC. Aspartic proteases of Plasmodium falciparum and other parasitic protozoa as drug targets. Trends Parasitol 2001;17(11):532-7.

[136] Wyatt DM, Berry C. Activity and inhibition of plasmepsin IV, a new aspartic proteinase from the malaria parasite, Plasmodium falciparum. FEBS Lett 2002;513(2-3):159-62.

[137] Francis SE, Sullivan Jr DJ, Goldberg DE. Hemoglobin metabolism in the malaria parasite Plasmodium falciparum. Annu Rev Microbiol 1997;51:97-123.

[138] Drew ME, Banerjee R, Uffman EW, Gilbertson S, Rosenthal PJ, Goldberg DE. Plasmodium food vacuole plasmepsins are activated by falcipains. J Biol Chem 2008;283(19):12870-6.

[139] Blackman MJ. Malarial proteases and host cell egress: an 'emerging' cascade. Cell Microbiol 2008;10(10):1925-34.

[140] Pang XL, Mitamura T, Horii T. Antibodies reactive with the N-terminal domain of Plasmodium falciparum serine repeat antigen inhibit cell proliferation by agglutinating merozoites and schizonts. Infect Immun 1999;67(4):1821-7.

[141] Miller SK, Good RT, Drew DR, Delorenzi M, Sanders PR, Hodder AN, et al. A subset of Plasmodium falciparum SERA genes are expressed and appear to play an important role in the erythrocytic cycle. J Biol Chem 2002;277(49):47524-32.

[142] Aly AS, Matuschewski K. A malarial cysteine protease is necessary for Plasmodium sporozoite egress from oocysts. J Exp Med 2005;202(2):225-30.

[143] Arastu-Kapur S, Ponder EL, Fonovic UP, Yeoh S, Yuan F, Fonovic M, et al. Identification of proteases that regulate erythrocyte rupture by the malaria parasite Plasmodium falciparum. Nat Chem Biol 2008;4(3):203-13.

[144] Yeoh S, O’Donnell RA, Koussis K, Dluzewski AR, Ansell KH, Osborne SA, et al. Subcellular discharge of a serine protease mediates release of invasive malaria parasites from host erythrocytes. Cell 2007;131(6):1072-83.

[145] Withers-Martinez C, Jean L, Blackman MJ. Subtilisin-like proteases of the malaria parasite. Mol Microbiol 2004:53(1):55-63.

[146] O'Donnell RA, Blackman MJ. The role of malaria merozoite proteases in red blood cell invasion. Curr Opin Microbiol 2005;8(4):422-7.

[147] O'Donnell RA, Hackett F, Howell SA, Treeck M, Struck N, Krnajski Z, et al. Intramembrane proteolysis mediates shedding of a key adhesin during erythrocyte invasion by the malaria parasite. J Cell Biol 2006;174(7):1023-33.

[148] Baker RP, Wijetilaka R, Urban S. Two Plasmodium rhomboid proteases preferentially cleave different adhesins implicated in all invasive stages of malaria. PLoS Pathog 2006;2(10):pe113.

[149] Lemberg MK, Freeman M. Functional and evolutionary implications of enhanced genomic analysis of rhomboid intramembrane proteases. Genome Res 2007;17(11):1634-46.

[150] Srinivasan P, Coppens I, Jacobs-Lorena M. Distinct roles of Plasmodium rhomboid 1 in parasite development and malaria pathogenesis. PLoS Pathog 2009;5(1):e1000262.
[151] Silvie O, Franetich JF, Renia L, Mazier D. Malaria sporozoite: migrating for a living. Trends Mol Med 2004;10(3):97-100, discussion 100-1.

[152] Harris PK, Yeoh S, Dluzewski AR, O’Donnell RA, Withers-Martinez C, Hackett $\mathrm{F}$, et al. Molecular identification of a malaria merozoite surface sheddase. PLoS Pathog 2005;1(3):241-51.

[153] Koussis K, Withers-Martinez C, Yeoh S, Child M, Hackett F, Knuepfer E, et al A multifunctional serine protease primes the malaria parasite for red blood cell invasion. Embo J 2009.

[154] Greenbaum DC, Baruch A, Grainger M, Bozdech Z, Medzihradszky KF, Enge $\mathrm{J}$, et al. A role for the protease falcipain 1 in host cell invasion by the human malaria parasite. Science 2002;298(5600):2002-6.

[155] Eksi S, Czesny B, Greenbaum DC, Bogyo M, Williamson KC. Targeted disruption of Plasmodium falciparum cysteine protease, falcipain 1, reduces oocyst production, not erythrocytic stage growth. Mol Microbiol 2004;53(1):243-50.

[156] Pandey KC, Singh N, Arastu-Kapur S, Bogyo M, Rosenthal PJ. Falstatin, a cysteine protease inhibitor of Plasmodium falciparum, facilitates erythrocyte invasion. PLoS Pathog 2006;2(11):e117.

[157] Bushell GR, Ingram LT, Fardoulys CA Cooper JA. An antigenic complex in the rhoptries of Plasmodium falciparum. Mol Biochem Parasito 1988;28(2):105-12.

[158] Howard RF, Reese RT. Plasmodium falciparum: hetero-oligomeric complexes of rhoptry polypeptides. Exp Parasitol 1990;71(3):330-42.

[159] Howard RF, Schmidt CM. The secretary pathway of Plasmodium falciparum regulates transport of p82/RAP1 to the rhoptries. Mol Biochem Parasitol 1995;74(1):43-54.

[160] Medzihradszky KF, Darula Z, Perlson E, Fainzilber M, Chalkley RJ, Ball H, et al. O-sulfonation of serine and threonine: mass spectrometric detection and characterization of a new posttranslational modification in diverse proteins throughout the eukaryotes. Mol Cell Proteomics 2004;3(5):429-40.

[161] Fennell BJ, Al-shatr ZA, Bell A. Isotype expression, post-translational modification and stage-dependent production of tubulins in erythrocytic Plasmodium falciparum. Int J Parasitol 2008;38(5):527-39.

[162] Banumathy G, Singh V, Pavithra SR, Tatu U. Heat shock protein 90 function is essential for Plasmodium falciparum growth in human erythrocytes. J Bio Chem 2003;278(20):18336-45.

[163] Pavithra SR, Kumar R, Tatu U. Systems analysis of chaperone networks in the malarial parasite Plasmodium falciparum. PLoS Comput Biol 2007;3(9):1701-15.

[164] Mouray E, Moutiez M, Girault S, Sergheraert C, Florent I, Grellier P. Biochemical properties and cellular localization of Plasmodium falciparum protein disulfide isomerase. Biochimie 2007;89(3):337-46.

165] Saridaki T, Sanchez CP, Pfahler J, Lanzer M. A conditional export system provides new insights into protein export in Plasmodium falciparum-infected erythrocytes. Cell Microbiol 2008;10(12):2483-95.

[166] Randow F, Lehner PJ. Viral avoidance and exploitation of the ubiquitin system. Nat Cell Biol 2009;11(5):527-34.

[167] Hamon MA, Cossart P. Histone modifications and chromatin remodeling during bacterial infections. Cell Host Microbe 2008;4(2):100-9.

168] Stulemeijer IJ, Joosten MH. Post-translational modification of host proteins in pathogen-triggered defence signalling in plants. Mol Plant Pathol 2008;9(4):545-60.

[169] Munro P, Flatau G, Lemichez E. Bacteria and the ubiquitin pathway. Curr Opin Microbiol 2007;10(1):39-46.

[170] Edelmann MJ, Kessler BM. Ubiquitin and ubiquitin-like specific proteases targeted by infectious pathogens: emerging patterns and molecular principles. Biochim Biophys Acta 2008;1782(12):809-16.

[171] Singh M, Mukherjee P, Narayanasamy K, Arora R, Gupta S, Natarajan K, et al. Proteome analysis of plasmodium falciparum extracellular secretory antigens at asexual blood stages reveals a cohort of proteins with possible roles in immune modulation and signaling. Mol Cell Proteomics 2009. 